Dhaka Univ. J. Biol. Sci. 19(2): 165-170, 2010 (July)

\title{
EFFECT OF MALE PARENTAL CARE ON REPRODUCTIVE SUCCESS OF BURYING BEETLES, NICROPHORUS VESPILLOIDES
}

\author{
SHARMIN MUSA* \\ Faculty of Life Sciences, University of Manchester, Stopford Building, \\ Oxford Road, Manchester, M13 9PT, UK
}

Key words: Parental care, Reproductive success, Burying beetles

\begin{abstract}
The burying beetles, Nicrophorus vespilloides (Coleoptera: Silphidae) show elaborate biparental care. They utilize a carcass as food of their own and to feed their offspring. Male parental care is important for both before and after the larvae hatch. But it is still not clear why male parents stay with the brood after the larvae hatch and provide care. The main objective of the study was to test whether male parents gain any future benefit from providing care that means access to carcass. Present investigation suggested previous parental care experience did not improve offspring fitness of future clutches. The offspring survival traits like number, average weight and development time showed no variation between clutches of experienced and inexperienced male parents.
\end{abstract}

\section{Introduction}

Burying beetles are a group of insect species that show biparental care.(1) Burying beetles breed on carcasses of small vertebrates and may require parental care to capitalise on this food resource. Parental care involve regurgitating carrion to the larvae, preparing the carcass, secreting antibacterial and proteolytic secretions to prevent bacterial growth and also defending the carcass brood.(2) Female parents stay until the larvae disperse while male parents leave two - three days earlier.

Males are expected to assist in defending the carcass as presence of two parents reduce chance of removing carcass by other conspecific competitors than when a female is breeding on her own. ${ }^{(3,4)}$ Nevertheless, males perform other forms of care for the offspring such as carcass maintenance and provisioning of food for the offspring. The benefit of male assistance in these behaviours is not clear because male removal in the absence of competitors has no effect on offspring growth or survival.(3,5-11)

Previous findings have shown that male parent's participation in pre-hatching care is important for offspring fitness. ${ }^{(12)}$ However, it is not yet clear why male beetles stay to perform post-hatching care beyond defence against competitors. Males may provide care to gain access to the carcass as a source of high-quality food which can be turned into a delayed benefit. Male beetles usually do not increase their resource holding potential but

*Present address: Department of Zoology, University of Dhaka, Dhaka-1000, Bangladesh. 
may gain delayed benefits by providing better care for future broods producing healthier offspring. If so, males may gain indirect benefits from previous parental care experience through the improved reproductive success of their offspring.

The present study tests the hypotheses that males which have previous parental care experience can improve their future reproductive success by comparing the reproductive fitness between males having previous parental care experience and males that had no such experience. There is evidence for genetic variation in the parental care provided by female burying beetles. ${ }^{(13)}$

Reproductive success among generations was measured, as parental effects may have an effect on the phenotype and fitness of the grandchildren.(15) Inherited environmental factors have shown influence over survival and fecundity of offspring.(14)

\section{Materials and Methods}

The experimental beetles were kept in clear plastic containers $(17 \times 12 \times 6 \mathrm{~cm})$ filled two/third with compost soil under $16: 8$ light : dark cycle at $20^{\circ} \mathrm{C}$ and fed decapitated mealworms (Tenebrio) ad libitum twice a week. Virgin males and females were randomly chosen from the stock population. All males and females were non-siblings.

One pair of males was chosen for each replica of the experiment $(n=46$ pairs of males). All males were placed in a separate plastic container $(17 \times 12 \times 6 \mathrm{~cm})$, filled two/third with compost soil and containing a female beetle. One male from each replicate was randomly removed from the container after $24 \mathrm{hr}$. These isolated males thus provided no parental care with access to carcass. The males were kept in the laboratory condition and fed mealworms ad libitum. The other male from each replicate was kept in its original container and provided a previously frozen mouse $(20-25 \mathrm{~g})$. Thus, these males could provide care and had access to a carcass by providing care. At the time that the larvae raised by the males had dispersed (defined as when larvae finish feeding from the carcass and wander around in the soil), the males were removed and kept under standard laboratory condition $\left(16: 8\right.$ light : dark cycle at $\left.20^{\circ} \mathrm{C}\right)$ and fed mealworms ad libitum.

Twenty four hr later one male that had previous parental care experience and had access to carcass and one male that had no such experience and access to carcass were mated with the same female. Randomly chosen, the male that first mated with female was placed in a plastic container, two/third full of soil and containing a previously frozen mouse (20 - $25 \mathrm{~g})$ and the female. These beetles were kept together to breed until the larvae dispersed. At the time of dispersal of the larvae, the male parent was killed by freezing while the female were put in a separate box with soil and kept in the laboratory. Forty eight hr later, the other male of the pair where given the same female, placed in a plastic container with two/third full of soil and a previously frozen mouse (20 - $25 \mathrm{~g})$ was 
provided. The mice of the two clutches of the same female were of similar weight $(<0.04 \mathrm{~g})$.

Effect of the male's previous parental care experience on brood size, average larval mass and offspring development time in and out of the carcass were recorded. These traits were chosen because Lock et al.(13) found that they correlate with larval survivorship. These traits were used to determine effect of parental care experience on future reproductive success of male beetles.

Total number and average weight of larvae at dispersal was counted and measured by weighing each larva in a Mettler analytical balance to the nearest $0.01 \mathrm{mg}$ and then taking the average value for each family. Dispersal time defined as the time from larval hatching to the time of dispersal from the carcass was recorded. The duration of the wandering stage was defined as the time each larva spent wandering in the soil after dispersing from the carcass until the onset of pupation. There is a negative correlation between time spent as wandering and time spent as pupae.(13,15) Therefore, calculation were made for time spent wandering as a proportion of total development time off the carcass (time spent wandering/(time spent wandering + time spent as pupae)) for individual larvae. Average of this value for each family was used in the analysis.

The effect of previous parental care experience of the male was also examined on the reproductive success of the offspring. Random selections of two daughters and two sons from each family which were mated with virgin beetles from the laboratory stock population were made. The pair was provided with 15 - $18 \mathrm{~g}$ mice and then was left until larvae dispersed. After larval dispersal individual larval mass from each family was recorded. The families where at least one male offspring and one female offspring had successfully reproduced were included in the analyses.

A repeated measure of ANOVA was performed comparing offspring fitness traits between the two clutches produced by each female (one produced with the assistance of a male that had previously provided care and one produced with the assistance of a male that not previously provided care). A two way ANOVA was performed to determine the affect of the grandfather's care experience on his grandchildren and to determine whether the effect is different for his daughter's family compared to his son's family.

\section{Results and Discussion}

Overall difference in offspring fitness traits between the clutches was not significant. The second brood that the females produced was significantly larger than the first brood (repeated measure ANOVA within-subjects effect: $F_{1,45}=11.53, P=0.001$ ), but did not depend on the experience of the male that the female first mated with (repeated measure ANOVA within-subjects effect $F_{1,45}=2.35, P=0.13$ ) (Table 1).

The average weight of larvae at dispersal was significantly heavier in the first brood that the females produced than the second brood (repeated measure ANOVA within- 
subjects effect: $F_{1,45}=9.85, P=0.003$ ) the difference did not depend on the experience of male the female was first mated with (repeated measure ANOVA within-subjects effect: $\left.F_{1,45}=0.22, P=0.64\right)($ Table 1$)$.

Table 1. Offspring fitness traits in first and second clutch of experienced and unexperienced male (Mean $\pm \mathrm{SE})$.

\begin{tabular}{lccccc}
\hline \multirow{2}{*}{ Trait } & \multicolumn{2}{c}{ Experienced male } & & \multicolumn{2}{c}{ Inexperienced male } \\
\cline { 2 - 3 } \cline { 5 - 6 } & First clutch & Second clutch & & First clutch & Second clutch \\
\hline $\begin{array}{l}\text { Number of larvae that } \\
\text { dispersed }\end{array}$ & $19.250 \pm 1.668$ & $24.895 \pm 2.197$ & & $22.263 \pm 2.025$ & $26.214 \pm 1.840$ \\
$\begin{array}{l}\text { Average weight of larvae at } \\
\text { dispersal (mg) }\end{array}$ & $0.159 \pm 0.004$ & $0.154 \pm 0.005$ & & $0.163 \pm 0.004$ & $0.148 \pm 0.004$ \\
$\begin{array}{l}\text { Development time on } \\
\text { carcass (days) }\end{array}$ & $5.929 \pm 0.153$ & $6.000 \pm 0.168$ & & $6.158 \pm 0.162$ & $6.179 \pm 0.138$ \\
$\begin{array}{l}\text { Proportion of time spent in } \\
\text { wandering stage }\end{array}$ & $0.501 \pm 0.009$ & $0.494 \pm 0.006$ & & $0.485 \pm 0.018$ & $0.493 \pm 0.005$ \\
\hline
\end{tabular}

There was also no significant difference between the clutches in terms of proportion of wandering stage (repeated measure ANOVA within-subjects effect: $F_{1,45}=0.050, P=$ $0.95)$ and there was no significant difference in proportion of wandering stage of the two clutches depending on which treatment male mated first with the female (repeated measure ANOVA within-subjects effect: $F_{1,45}=1.49, P=0.23$ ).

No significant effect of the previous experience with providing care on number of offspring that dispersed were evident (grandfather effect $F_{1,152}=0.512, P=0.476$, maternal or paternal effect $F_{1,152}=0.846, P=0.359$, interaction effect $F_{1,152}=1.764, P=0.186$ ). Likewise, the male's previous engagement in care had no significant effects on average weight of larvae at dispersal (grandfather effect $F_{1,152}=1.825, P=0.179$, maternal or paternal effect $F_{1,152}=0.327, P=0.568$, interaction effect $F_{1.152}=1.594, P=0.209$ ) (Table 1).

Present study implied that there was difference between the two clutches by the female, but this difference was independent on which male the female first mated with. Females produced small number of heavier larvae in their first clutch and large number of lighter larvae in their second clutch. This trade off between larval number and offspring has also been found in other burying beetle studies. ${ }^{(5,4,16)}$ It might be that in the second clutch they are able to produce more eggs as they gain resources from previous access to carcass during parental care. However, as the carcass is limited there is less food for each individual offspring compelling the female to produce large number of smaller offspring.

No difference in development time between the male groups was obtained. A shorter development time for broods was expected of males that had previously provided care. There is strong selection for short development time in burying beetles.(13) It has been 
found that development time of larvae both inside and outside the carcass strongly depended on carcass size in burying beetle studies.(15) As mouse size was similar in between our two groups there might be no difference in development time between the broods of two groups. No effect of previous parental care experience by males on the reproductive success of offspring was apparent. Therefore, previous experience of male care did not improve fitness of grandchildren.

In conclusion, there was no evidence that male burying beetles perform posthatching care to improve their future reproductive success. Perhaps male beetles are performing post-hatching care gain some other benefit which have not been measured during this study. It might be that they are using the experience from parental care and energy from the foraging the carcass not in reproduction but to improve their health to fight against diseases, improve their flight efficiency and ability to search resources.

\section{Acknowledgements}

This is part of Ph.D. thesis of the author. The author is grateful to Professor Allen J. Moore and Dr. Per T. Smiseth, University of Manchester for their guidance and support. Author is also grateful to Ministry of Science and Technology, Government of the People's Republic of Bangladesh for financial support.

\section{References}

1. Eggert AK and JK Müller 1997. Biparental care and social evolution in burying beetles: Lessons from the larder. In: The Evolution of Social Behavior in Insects and Arachnids. (Choe JC and BJ Crespi Eds.). pp. 216-236. Cambridge University Press, Cambridge.

2. Eggert AK, M Reinking and JK Müller 1998. Parental care improves offspring survival and growth in burying beetles. Anim. Behav. 55: 97-107.

3. Scott MP 1989. Male parental care and reproductive success in the burying beetle Nicrophorus orbicollis. J. Insect. Behav. 2: 133-137.

4. Trumbo ST 1990. Brood size regulation in a burying beetle, Necrophorus tomentosus. J. Insect. Behav. 3:491-500.

5. Barlett J and CM Ashworth 1988. Brood size and fitness in Necrophorus vespilloides (Coleoptera: Silphidae). Behav. Ecol. Sociobiol. 22: 429-434.

6. Reinking M and JK Müller 1990. The benefit of parental care in the burying beetle, Necrophorus orbicollis (Coleoptera: Silphidae). J. Zool. (London). 231: 583-593.

7. Trumbo ST 1991. Reproductive benefits and the duration of paternal care in a biparental burying beetle, Necrophorus orbicollis. Behaviour 117: 82-105.

8. Trumbo ST and AG Fernandez 1995. Regulation of brood size by male parents and cues employed to assess resource size by burying beetles. Ethol. Ecol. Evol. 7: 313-322.

9. Müller JK, AK Eggert and SK Sakaluk 1998. Carcass maintenance and biparental brood care in burying beetles: Are males redundant? Ecol. Entomol. 23: 195-200.

10. Jenkins EV, C Morris and S Blackman 2000. Delayed benefits of paternal care in the burying beetle Nicrophorus vespilloides. Anim. Behav. 60: 443-451. 
11. Satou A, T Nisimura and H Numata 2001. Cost and necessity of parental care in the burying beetle Nicrophorus quadripunctatus. Zool. Science 18: 975-979.

12. Musa S 2005. Cost and benefit of conflict and co-operation in burying beetles Nicrophorus vespilloides. Ph.D. Thesis, Faculty of Life Sciences, University of Manchester, pp. 147.

13. Lock JE, PT Smiseth and AJ Moore 2003. Selection, inheritance and the evolution of parentoffspring interactions. Am. Nat. 164: 1-24.

14. Rossiter M 1996. Incidence and consequences of inherited environmental effects. Ann. Rev. Ecol. System. 27: 451-476.

15. Rauter CM and AJ Moore 2002. Quantitative genetics of growth and development time in the burying beetle Nicrophorus pustulatus in the presence and absence of post-hatching parental care. Evolution 56: 96-110.

(Manuscript received on 22 November, 2009; revised on 21 March, 2010) 